\title{
Effects of Topical Carbonic Anhydrase Inhibitors on the Olfactory Sense
}

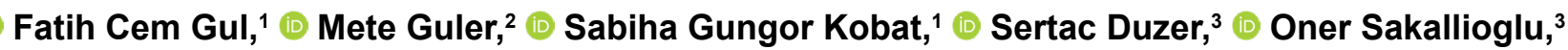 \\ Fatih Celik, ${ }^{1}$ (1) Abdulvahap Akyigit ${ }^{4}$
}

${ }^{1}$ Department of Ophthalmology, Health and Science University, Elazig Fethi Sekin City Hospital, Elazig, Turkey

2Department of Ophthalmology, Kahramanmaras Sutcu Imam University, Kahramanmaras, Turkey

${ }^{3}$ Department of Ent, Health and Science University, Elazig Fethi Sekin City Hospital, Elazig, Turkey

${ }^{4}$ Department of ENT, Firat University, Elazig, Turkey

\begin{abstract}
Objectives: The sense of smell plays an important role in daily life. Olfactory impairment can significantly affect an individual's quality of life. Topical carbonic anhydrase inhibitors are commonly used to treat elevated intraocular pressure (IOP). One potential side effect of these drugs is a loss of the sense of smell. This study is an examination of changes in olfactory function in patients who used dorzolamide and brinzolamide to control IOP after a laser capsulotomy.

Methods: A total of 60 patients with posterior capsule opacification were included in the study. Sniffin' Sticks (Burghart Messtechnik $\mathrm{GmbH}$, Wedel, Germany) were used to evaluate patient olfactory sensitivity before starting the topical treatment and after I week of treatment.

Results: No statistically significant decrease in olfactory performance was observed in users of either brinzolamide or dorzolamide ( $\mathrm{p}=0.705, \mathrm{p}=0.405$ respectively).

Conclusion: No negative effect on the sense of smell was determined after 7 days of topical application of a carbonic anhydrase enzyme inhibitor to the eye in patients with no previous anosmia.

Keywords: Brinzolamide, dorzolamide, smell, Sniffin' Sticks, treatment
\end{abstract}

\section{Introduction}

The sense of smell plays a significant role in daily life, and olfactory impairment can have a notable effect on quality of life. When the ability to differentiate between different odors is lost, not only is enjoyment of food and beverages diminished, awareness of some potential dangers is reduced (I). Enhanced sensitivity in the sense of smell can also have substantial effects and result in nausea, sneezing, headaches, and pain in the eyes (2-3). An unrecognized smell disorder can contribute to a range of conditions, including, but not limited to, environmental and social anxiety, nutritional disorders, and depression (4).

Olfaction originates in specialized olfactory sensory neurons, which are found in tissue high inside the nose. A variety of causes can contribute to disorders of the sense of smell, which have been reported to affect $21.6 \%$ of the general

How to cite this article: Gul FC, Guler M, Gungor Kobat S, Duzer S, Sakallioglu O, Celik F, et al.. Effects of Topical Carbonic Anhydrase Inhibitors on the Olfactory Sense. Beyoglu Eye J 202I; 6(I): 19-23.

Address for correspondence: Fatih Cem Gul, MD. Goz Hastaliklari Bolumu, Saglik ve Bilim Universitesi, Elazig Fethi Sekin Sehir Hastanesi, Elazig, Turkey

Phone: +90 5053487427 E-mail: fatihcemgul@gmail.com

Submitted Date: September 02, 2020 Accepted Date: January 16, 2021 Available Online Date: February 13, 2021

${ }^{\circ}$ Copyright 2021 by Beyoglu Eye Training and Research Hospital - Available online at www.beyoglueye.com 
population (6). Each year, almost 200.000 people in the USA seek treatment for olfactory disorders (7).

Carbonic anhydrase inhibitors (CAls) are a common ingredient in eye drop solutions used to treat glaucoma. However, local and systemic side effects may hamper their clinical usefulness. Topical $2 \%$ dorzolamide and topical $1 \%$ brinzolamide are often used as monotherapy 3 times a day to reduced intraocular pressure (IOP). When dorzolamide is used as monotherapy, IOP typically falls by $10 \%$ to $26 \%$, and a decrease of $15 \%$ to $21 \%$ has been observed with the use of brinzolamide $(8,9)$. Side effects of eye pain, burning, stinging, conjunctival hyperemia, and a sour taste in the mouth may occur with the use of dorzolamide (10). Brinzolamide has similar side effects, though less eye pain has been reported (II).

To the best of our knowledge, there is no previous study in literature designed to investigate effects on the sense of smell related to use of topical CAls. The aim of this study was to evaluate changes in olfactory function by measuring pre- and posttreatment olfactory sensitivity using the Sniffin' Sticks (Burghart Messtechnik GmbH, Wedel, Germany) test on patients who used a topical CAl treatment to reduce IOP.

\section{Methods}

This study included 60 eyes of 60 patients, who presented at Elazig Fethi Sekin City Hospital Ophthalmology Department between January and December 20I8, were diagnosed with posterior capsule opacity, were treated with yttrium-aluminum garnet (YAG) laser capsulotomy, and began topical CAI treatment. In all cases, there were no complications during the phacoemulsification surgery, and at least 6 months had passed since the surgery. In addition, the patients had not used any topical or systemic drug treatment for at least I month prior to the study.

All of the participants underwent a screening process with a complete ophthalmological examination, including evaluation of refraction and visual acuity, slit-lamp biomicroscopy, IOP measurement using non-contact tonometry, and a fundus examination. Patients who had glaucoma, corneal or retinal disease, uveitis, previous laser treatments, ocular trauma, or surgery during the follow-up period were excluded from the study.

The 12-item Sniffin' Sticks screening test is a multiple-choice test used to distinguish normal and impaired olfactory function. The individual being tested is asked to identify 12 different common odors using a choice of 4 responses. The patient must select only I answer and there is no option of "odorless." The result is defined by the total of correctly identified odors. A score of $>10$ indicates normal olfactory function, between 6 and 10 indicates low olfactory performance, and a score of $<6$ signifies the presence of severe olfactory impairment.
All of the study patients underwent a thorough ear, nose and throat (ENT) examination. Patients with a deviated septum, nasal polyps, concha hypertrophy, upper respiratory tract infection within the previous 10 days, acute-chronic sinusitis, allergic rhinitis, or a history of head trauma, previous nasal surgery, nasolacrimal duct occlusion, radiotherapy to the head, or use of pharmacotherapy known to impair olfactory functions were excluded from the study. A single ENT specialist administered the olfactory function tests to those who fulfilled the inclusion criteria. The patients were instructed to close their eyes during the test to eliminate any visual influence. The test was performed by holding the Sniffin' Stick pen approximately $2 \mathrm{~cm}$ in front of the nostrils for 3 to 4 seconds and then the cap was replaced. The test subject was given a choice of 4 responses for each odor presented. The study group comprised 2 groups: 30 patients who used topical $3 \times 1$ brinzolamide treatment after the YAG laser capsulotomy and 30 patients who used topical $3 \times 1$ dorzolamide treatment. The Sniffin Sticks evaluation was performed before starting the topical treatment and after I week of treatment.

This prospective study was performed in the ophthalmology department of Elazig Fethi Sekin City Hospital. The study adhered to the tenets of the Declaration of Helsinki and was approved by the Noninvasive Research Ethics Committee of Firat University on November 22, 2018 (no: 19/3). Oral and written information regarding the study was provided to the participants, and each subject submitted written, informed consent before the study was initiated.

\section{Statistical Analysis}

The study data were analyzed using IBM SPSS Statistics for Windows, Version 22.0 (IBM Corp., Armonk, NY, USA). The Wilcoxon t-test was used for paired comparisons. A value of $\mathrm{p}<0.05$ was accepted as statistically significant.

\section{Results}

The study group comprised 14 males and 16 females with a mean age of $56.63 \pm 4.47$ years in the brinzolamide treatment group, and 13 males and 17 females with a mean age of $56.5 \pm 3.32$ years in the dorzolamide treatment group. The mean pretreatment Sniffin' Sticks score was $11.16 \pm 2.3$ in the brinzolamide group and $11.16 \pm 1.47$ in the dorzolamide group. The mean posttreatment score was $11.13 \pm 2.28$ in the brinzolamide group and II.16 \pm 1.14 in the dorzolamide group. No statistically significant change was noted in olfactory performance after a week of topical treatment with brinzolamide ( $p>0.05)$ (Fig. I). The Sniffin' Sticks test results after a week of topical treatment with dorzolamide also revealed no statistically significant change $(p>0.05)$ (Fig. 2). The study results indicated that topical CAI treatment had no effect on odor identification following I week of use. 


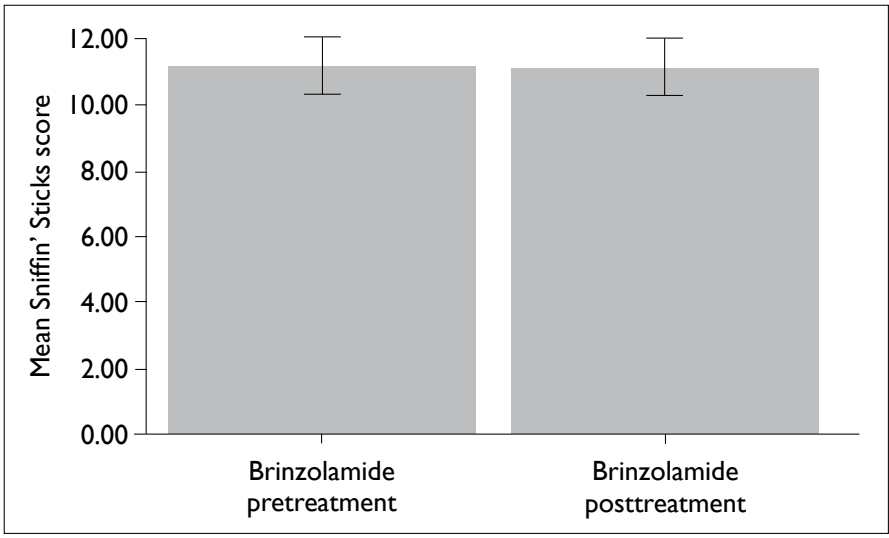

Figure I. Sniffin' Sticks score before and after brinzolamide treatment.

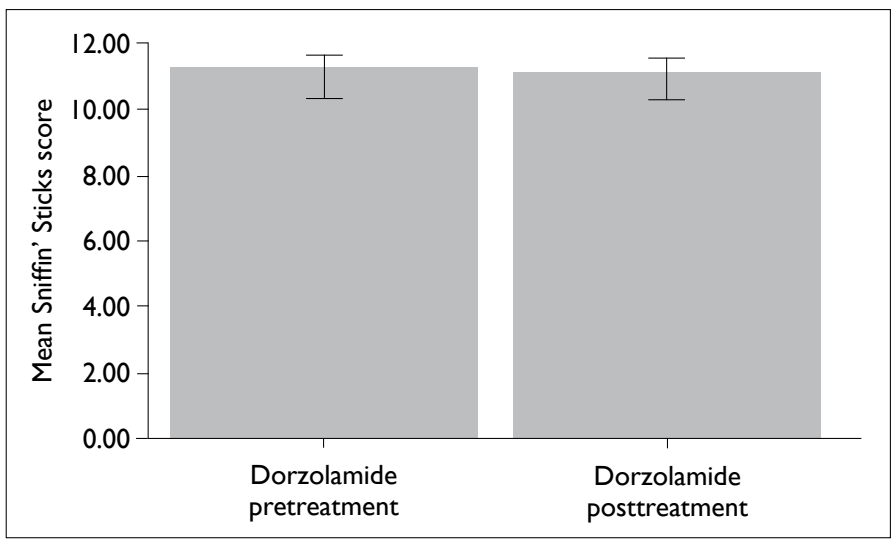

Figure 2. Sniffin' Sticks score before and after dorzolamide treatment.

\section{Discussion}

Carbonic anhydrase (CA) enzyme expression has been detected in the olfactory mucosa and in the olfactory receptor neurons. The effects of CA on central and arterial chemoreceptors are well known $(12,13)$. However, the effects on taste, smell, and the somatosensorial area are more recent observations.

Okamura et al. (14) reported CA activity in the saliva glands, tongue, nasal mucosa, and the Bowman's gland. CA activity has been reported in the olfactory system of frogs and in the rostracaudal cells of the olfactory epithelium in guinea pigs using histochemical techniques (15-17). However, the functions are not yet fully understood.

CA activity appears to have multiple effects. It has been found to play a role in substrate formation at the tissue and cellular level in hemostatic ion processes and in the removal of metabolic waste (18). Sensorineural activity in the tissue where $C A$ is found changes the interstitial ionic surroundings and the mucosal composition. CA enzyme activity appears to be very important for the sense of smell and taste, stability of the receptor environment, and the direct transmission of the quality and quantity of the stimulus and encoding.

Kim et al. (19) suggested that the CA enzyme has a role in the regulation of nasal secretions and the pathogenesis of nasal polyps. Previous studies have identified CA I, 2, 3, 4, $5 a, 5 b, 6,7,9,12,14$ isoenzymes in normal mucosa, with 14, 2, 4 and $5 \mathrm{~b}$ isoenzyme forms present in the largest quantity.

It has been reported that systemic inhibition $(250 \mathrm{mg} /$ day) of CA can lead to a reduction in the sense of taste (20). This is a result of effects to the seventh and ninth cranial nerves (2I). Impairment of the sense of taste has also been shown to occur with topical CAl application (22). Since effects have been seen with topical and systemic use, and given that the senses of taste and smell are linked, it is not unreasonable to think that the use of CAI might affect the olfactory system.

Previous studies have determined changes in the pathways related to the nasal mucosa and carbon dioxide in the oral cavity. However, in rat model studies, CA mediation did not result in impairment of the sense of smell. This may be because the CA receptors are located in the peripheral mucosa (2I). To the best of our knowledge, there are no extensive series in the literature that have reported that topical CAI treatment led to impairment of the sense of smell. The results of the current study demonstrated no impairment of olfactory ability after topical CAl treatment for I week.

In a study conducted with a group of patients who had developed smell and taste distortion following acute influenza-like disease, a significantly low level of zinc concentration was identified, and the disease was named idiopathic hyposmia and hypogeusia $(23,24)$. Purified gustin, which is a zinc-binding metalloprotein, was used in studies conducted to determine the underlying mechanisms. Subsequent studies examined the amino acid level and biochemical structure, and found that the gustin molecule was identical to CA 6 (25,26). Increased synthesis/secretion of gustin/CA 6 with zinc treatment proved to be effective in most patients (27). Previous animal and human studies of zinc deficiency have demonstrated a similarity to the mechanisms seen in idiopathic hyposmia and hypogeusia patients. It has been proposed that a zinc deficiency affects CA enzyme activity. The smell and taste impairments seen in xerostomia and xerorhinia patients have also been shown to improve following zinc treatment (28).

A decrease in the gustin/CA 6 complex has been determined in the saliva of patients with a CA 2 deficiency. This disease is characterized by short height, osteoporosis, cerebral calcification, renal tubular acidosis, mental retardation, anorexia, and anosmia despite normal nasal anatomy. The enzyme activity of CA is thought to play a role in the biochemical basis of the sense of smell.

Tarun et al. (29) examined the CA enzyme in human nasal mucosa and it was reported that there may be individual variations in certain isoenzyme forms, which could affect the 
carbon dioxide chemosensitivity mediated by CA.

Turgut et al. (30) reported that glaucoma treatment with dorzolamide appeared to result in anosmia. A loss of the sense of smell began I month after dorzolamide was added to timolol, and was complete in 2 months. Once the CAI was eliminated from treatment, the smell impairment resolved in 20 days. As this effect did not occur in all patients, this may have been due to intrapersonal enzyme variations.

In the current study, CAl use was not determined to have a negative effect on the sense of smell in a 7-day period. However, further studies with longer follow-up periods are needed to fully determine the effect of enzyme activity on anosmia. The short follow-up period can be considered a limitation of our research.

CA enzyme activity has been determined histochemically in human and animal nasal mucosa, and in some diseases that progress with smell and taste impairment it is thought that impaired enzyme activity may be important in the etiology of the disease. In the current study, CA enzyme inhibitors applied topically to the eye were not determined to have a negative effect on the sense of smell in patients with no previous olfactory impairment. Nonetheless, additional limitations of the present study and areas for further research include examining the quantity of the drug reaching the nasal mucosa via the nasolacrimal canal and possible intrapersonal enzyme variations.

\section{Conclusion}

The results of this study revealed no negative effect on the sense of smell as a result of a CAI applied topically to the eye for 7 days in patients with no previous smell impairment. There is a need for further studies with a larger patient group and a longer study period to more precisely determine the effect of enzyme activity on anosmia. Topical application could be made directly to the nasal mucosa, and histochemical studies could be conducted to determine the $\mathrm{CA}$ isoenzyme forms in the nasal mucosa.

\section{Disclosures}

Ethics Committee Approval: This prospective study was performed in the ophthalmology department of Elazig Fethi Sekin City Hospital. The study adhered to the tenets of the Declaration of Helsinki and was approved by the Noninvasive Research Ethics Committee of Firat University on November 22, 2018 (no: 19/3).

Peer-review: Externally peer-reviewed.

Conflict of Interest: None declared.

Authorship Contributions: Involved in design and conduct of the study (FCG, MG); preparation and review of the study (FCG, MG); data collection (FCG, SGK, FÇ, SD, OS, AA); and statistical analysis (SD, OS).

\section{References}

I. Frasnelli J, Hummel T. Olfactory dysfunction and daily life. Eur Arch Otorhinolaryngol 2005;262:23I-5. [CrossRef]

2. Heinrichs L. Linking olfaction with nausea and vomiting of pregnancy, recurrent abortion, hyperemesis gravidarum, and migraine headache. Am J Obstet Gynecol 2002; 186:2 15-9. [CrossRef]

3. Hummel T, von Mering R, Huch R, Kölble N. Olfactory modulation of nausea during early pregnancy? BJOG 2002;109:1394-7.

4. Croy I, Nordin S, Hummel T. Olfactory disorders and quality of life-an updated review. Chem Senses 20 I4;39:185-94. [CrossRef]

5. Imamura F, Hasegawa-Ishii S. Environmental toxicants-induced immune responses in the olfactory mucosa. Front Immunol 2016;4:475. [CrossRef]

6. Vennemann MM, Hummel T, Berger K. The association between smoking and smell and taste impairment in the general population. J Neurol 2008;255: I 12 I-6. [CrossRef]

7. Dalton P. Olfaction and anosmia in rhinosinusitis. Curr Allergy Asthma Rep 2004;4:230-6. [CrossRef]

8. Lippa EA, Schuman JS, Higginbotham EJ, Kass MA, Weinrib RN, Skuta GL, et al. MK-507 versus sezolamide: a comparative efficacy of two topically active carbonic anhydrase inhibitors. Ophthalmology 1991;98:308-12. [CrossRef]

9. Lippa EA, Carlson LE, Ehinger B, Eriksson LO, Finnstrom K, Holmin C, et al. Dose response and duration of action of dorzolamide, a topical carbonic anhydrase inhibitor. Arch Ophthalmol 1992; I 10:495-9. [CrossRef]

10. Kitazawa Y, Azuma I, Iwata K, Tsukahara S, Shioes Y, Araie M, et al. Dorzolamide, a topical carbonic anhydrase inhibitor: a twoweek dose response study in patients with glaucoma or ocular hypertension. J Glaucoma 1994;3:275-79. [CrossRef]

II. Stewart R, the Brinzolamide Comfort Study Group. The ocular comfort of the TID-dosed brinzolamide $1.0 \%$ compared to TID-dosed dorzolamide $2.0 \%$ in patients with primary open-angle glaucoma or ocular hypertension. Invest Ophthalmol Vis Sci 1997;38:2603.

12. Neubauer JA, Carbonic anhydrase and sensory function in central nervous system. In: SJ Dodgson, RE Tashian, G Gros, ND Carter, editors. The Carbonic Anhydrase-Cellular Physiology and Molecular Genetics. New York: Plenum Press; 1991. [CrossRef]

13. Lahiri S, Carbonic anhydrase and chemoreception in carotid and aortic bodies Chapter 30. In: SJ Dodgson, RE Tashian, G Gros, ND Carter, editors. The Carbonic Anhydroses: Cellular Physiology and Molecular Genetics. New York: Plenum Press; 1991. [CrossRef]

14. Okamura H, Sugai N, Ohtani I. Identification of nasal epithelial cells with carbonic anhydrase activity. Brain Res 1996;728:2636. [CrossRef]

15. Aramaki S, Yoshida I, Yoshino M, Kondo M, Sato Y, Noda K, et al. Carbonic anhydrase II deficiency in three unrelated Japanese patients. J Inherit Metab Dis 1993;16:982-90. [CrossRef] 
16. Coates El, Wells CM, Smith RP. Identification of carbonic anhydrase activity in bullfrog olfactory receptor neurons: histochemical localization and role in $\mathrm{CO} 2$ chemoreception. J Comp Physiol 1998; 182:163-74. [CrossRef]

17. Baradi AF, Bourne GH. Gustatory and olfactory epithelia. Int Rev Cytol 1953;2:289-330. [CrossRef]

18. Wong V, Barrett CP, Donati EJ, Eng LF, Guth L. Carbonic anhydrase activity in first-order sensory neurons of the rat. J Histochem Cytochem 1983;31:293-300. [CrossRef]

19. Kim TH, Lee HM, Lee SH, Kim HK, Lee JH, Oh KH, et al. Down-regulation of carbonic anhydrase isoenzymes in nasal polyps. Laryngoscope 2008; I 18:1856-6I. [CrossRef]

20. Miller LG, Miller SM. Altered taste secondary to acetozolamide therapy. J Family Pract 1990;31:19-200.

21 . Bruce PB. The roles of carbonic anhydrase in gustation, olfaction and chemical irritation. EXS 2000;90:365-74. [CrossRef]

22. Graber M, Kelleher S. Side effects of acetozalamide: The champagne blues. Am J Med 1992;84:979-80. [CrossRef]

23. Henkin RI, Schechter PJ, Hoye R, Mattern CF. Idiopathic hypogeusia with dysgeusia, hyposmia, and dysosmia. A new syndrome. JAMA 1971;217:434-40. [CrossRef]
24. Henkin RI, Larson AL, Powell RD. Hypogeusia, dysgeusia, hyposmia, and dysosmia following influenza like infection. Ann Otol Rhinol Laryngol 1975;84:672-82. [CrossRef]

25. Henkin RI, Martin BM, Agarwal RP. Carbonic anhydrase VI deficiency: a viral induced disorder amenable to treatment with exogenous zinc. J Invest Med 1995;43:242.

26. Thatcher BJ, Doherty AE, Orvisky E, Martin BM, Henkin RI. Gustin from human parotid saliva is carbonic anhydrase (CA) VI. Biochern Biophys Res Commun 1998;250:635-4I. [CrossRef]

27. Henkin RI, Martin BM, Agarwal RP. Efficacy of exogenous oral zinc in treatment of patients with carbonic anhydrase $\mathrm{VI}$ deficiency. Am J Med Sci 1999;3 18:392-405. [CrossRef]

28. Henkin RI, Talal N, Larson AL, Mattern CF. Abnormalities of taste and smell in Sjogren's syndrome. Ann Intern Med 1972;76:375-83. [CrossRef]

29. T arun AS, Bryant B, Zhai W, Solomon C, Shusterman D. Gene expression for carbonic anhydrase isoenzymes in human nasal mucosa. Chem Senses 2003;28:621-9. [CrossRef]

30. Turgut B, Türkçüoğlu P, Güler M, Akyol N, Celiker U, Demir T. Anosmia as an adverse effect of dorzolamid. Acta Ophthalmol Scand 2007;85:228-9. [CrossRef] 